\title{
Avaliação da atividade antimicrobiana do óleo essencial de sucupira (Pterodon emarginatus Vogel)
}

\author{
FERREIRA, S.B. ${ }^{1, *}$; DANTAS, I.C..; CATÃO, R.M.R. ${ }^{3}$ \\ ${ }^{1}$ Farmacêutico graduado pela Universidade Estadual da Paraíba; Rua Baraúnas, 351 - Bairro Universitário -CEP \\ 58429-500, Campina Grande - Brasil; ${ }^{2}$ Professor Mestre do Centro de Ciências Biológicas da Universidade \\ Estadual da Paraíba; Rua Baraúnas, 351-Bairro Universitário - CEP 58429-500, Campina Grande - Brasil; \\ ${ }^{3}$ Professora Doutora do Departamento de Farmácia da Universidade Estadual da Paraíba; Rua Baraúnas, \\ 351-Bairro Universitário -CEP 58429-500, Campina Grande Brasil
}

\begin{abstract}
RESUMO: A utilização de plantas com fins terapêuticos é uma das mais antigas formas de prática medicinal da humanidade. Isso tem despertado o interesse científico através de estudos sobre as atividades antimicrobianas de extratos e óleos essenciais de plantas com a finalidade de criar alternativas para o combate aos microrganismos resistentes aos antimicrobianos disponíveis atualmente. O objetivo deste estudo foi avaliar a possível atividade antimicrobiana do óleo essencial de Pterodon emarginatus Vogel frente às cepas bacterianas padrão de Staphylococcus aureus ATCC 25923, Pseudomonas aeruginosa ATCC 27853 e Escherichia coli ATCC 25922. O óleo essencial de $P$. emarginatus foi extraído através do método de hidrodestilação por arraste a vapor utilizando aparelho de Clevenger modificado. A atividade antimicrobiana foi determinada utilizando o método de difusão em meio sólido, pela técnica de pour plate, usando o óleo essencial puro (100\%) e nas seguintes diluições: $32 \%, 16 \%, 8 \%, 4 \%, 2 \%, 1 \%$ e $0,5 \%$. Nenhuma das concentrações testadas do óleo essencial formou halo de inibição para as cepas de Staphylococcus aureus ATCC 25923, Pseudomonas aeruginosa ATCC 27853 e Escherichia coli ATCC 25922. Dessa forma, conclui-se que o óleo essencial de $P$. emarginatus não possui atividade antimicrobiana contra S. aureus, P. aeruginosa e E. coli.
\end{abstract}

Palavras-chave: Pterodon emarginatus, Plantas medicinais, Óleos essenciais.

ABSTRACT: Evaluation of the antimicrobial activity of the essential oil of sucupira (Pterodon emarginatus). The use of plants for therapeutic purposes is one of the oldest forms of medical practice. This has aroused scientific interest through studies on the antimicrobial activity of extracts and essential oils from plants for the purpose of creating alternatives to combat microorganisms resistant to antibiotics. The objective of this study was to evaluate the potential antimicrobial activity of the essential oil of Pterodon emarginatus against Staphylococcus aureus ATCC 25923, Pseudomonas aeruginosa ATCC 27853 and Escherichia coli ATCC 25922. The essential oil of $P$. emarginatus was extracted by the method of hydrodistillation by steam distillation using a modified Clevenger apparatus. Antimicrobial activity was determined using the method of diffusion in solid medium by the pour plate technique using pure essential oil (100\%) at the following concentrations: $32 \%, 16 \%, 8 \%, 4 \%, 2 \%, 1 \%$ and $0.5 \%$. None of the concentrations formed zones of inhibition for Staphylococcus aureus ATCC 25923, Pseudomonas aeruginosa ATCC 27853 and Escherichia coli ATCC 25922. The present findings suggest that the essential oil of $P$. emarginatus has no antimicrobial activity against $S$. aureus. $P$. aeruginosa and $E$. coli.

Keywords: Pterodon emarginatus, Medicinal plants, Essential oils.

\section{INTRODUÇÃO}

O emprego de plantas com fins medicinais para tratamento, cura, e prevenção de doenças é uma das mais antigas formas de prática medicinal da humanidade onde diversas culturas se valeram das plantas medicinais, sendo esta a principal ou a única matéria prima para elaboração de medicamentos. O conhecimento sobre o potencial terapêutico dos vegetais tem despertado interesse científico, buscando, nesse conhecimento, novos caminhos para o controle e tratamento de diversas 
doenças. A partir desses dados etnofarmacológicos passados por gerações e com o desenvolvimento da ciência e da tecnologia, um maior número de plantas medicinais estão tendo seu valor terapêutico pesquisado, resultando em maior número de compostos naturais, conhecidos como metabólitos secundários (VEIGA JÚNIOR; PINTO, 2005; LÓPEZ, 2006).

Graças a sua atividade metabólica secundária, os vegetais superiores são capazes de produzir substâncias antibióticas utilizadas como mecanismo de defesa contra predação por micro-organismos, insetos e herbívoros. As propriedades antimicrobianas dessas substâncias também são reconhecidas empiricamente há séculos e estão sendo comprovadas cientificamente apenas recentemente. Estudos sobre as atividades antimicrobianas de extratos e óleos essenciais de plantas nativas têm sido relatado em muitos países, inclusive no Brasil, que possui flora diversificada e rica tradição na utilização de plantas medicinais como antibacteriano, antifúngico, anti - inflamatório, entre outros. Em meio ao grande número de espécies de plantas com propriedades terapêuticas encontrase a sucupira-branca, identificada botanicamente como Pterodon emarginatus e conhecida também como fava-de-santo-inácio (DUARTE, 2006; NEVES et al., 2007).

Esta planta pertence à família Fabaceae e pode ser encontrada em todo cerrado brasileiro e em áreas de transição. Todas as partes da planta são utilizadas na medicina popular, desde a raiz até as folhas, sob a forma de infusão e decocção, tendo como principais usos: no tratamento da diabetes, do reumatismo, e como anti-inflamatório. Várias pesquisas sobre a atividade biológica da $P$. emarginatus vêm sendo desenvolvidas recentemente (PAULA et al., 2005; MORAES et al., 2009; SANTOS et al., 2010; GALCERAN et al., 2011).

As plantas medicinais produzem grande variedade de substâncias com distintas propriedades, dentre elas, a atividade antimicrobiana. Espera-se que programas de triagem possam descobrir compostos candidatos para o desenvolvimento de novos fármacos, a fim de fornecer alternativas para o combate de microrganismos resistentes as drogas disponíveis atualmente. (AHMAD; BEG, 2001)

O problema da resistência microbiana é crescente e nenhuma nova classe de antimicrobiano foi descoberta nos últimos anos, apesar das intensas pesquisas das indústrias farmacêuticas (DUARTE, 2006). Desse modo, a perspectiva de uso de drogas antimicrobianas no futuro é incerta (NASCIMENTO et al., 2000).

Cria-se, nesse cenário, a necessidade de realizar investigações científicas que visem determinar o potencial antimicrobiano das plantas medicinais. Embora tenha havido registros da atividade antimicrobiana do óleo essencial de $P$. emarginatus, não houve nenhuma investigação da sua atividade nas linhagens utilizadas neste estudo. Assim, neste contexto, o presente trabalho teve como objetivo avaliar a possível atividade antimicrobiana frente a cepas bacterianas, onde foram realizados testes in vitro de susceptibilidade dos micro-organismos de importância clínica diante do óleo essencial da $P$. emarginatus.

\section{METODOLOGIA}

\section{Coleta do material vegetal}

Foi adotado como critério de seleção da espécie vegetal o uso popular da semente da sucupira como adjuvante nas infecções de garganta, utilização esta empregada durante muitos anos na cidade de Itaueira - PI. As sementes de Pterodon emarginatus Vogel foram coletadas de plantas adultas localizadas na zona rural do município no mês de janeiro de 2009 e armazenadas em um recipiente plástico com tampa ao abrigo da luz e da umidade. A identificação botânica foi realizada pelo biólogo Ivan Coêlho Dantas no Laboratório de Farmacobotânica da Universidade Estadual da Paraíba.

\section{Extração do óleo essencial}

As sementes foram secas a temperatura ambiente devido à sensibilidade dos compostos essenciais a temperaturas elevadas.

As sementes foram trituradas manualmente para aumentar a área superficial de contato, semente-água, sendo em seguida submetidas à extração. Foram pesados $200 \mathrm{~g}$ das sementes e acrescentado $1000 \mathrm{~mL}$ de água e colocadas em balão de fundo redondo deixando-se em ebulição por 4 horas controlando-se a temperatura em, aproximadamente, $100^{\circ} \mathrm{C}$.

A extração do óleo essencial foi realizada no Laboratório de Farmacognosia da Universidade Estadual da Paraíba no mês de Junho de 2009. O método de extração escolhido foi a hidrodestilação em Clevenger modificado, de acordo com o preconizado pela Farmacopéia Brasileira IV (SIMÕES et al., 2003). Em seguida, a solução água-óleo foi recolhida no decantador e seus componentes separados por diferença de densidade. Com o auxílio de uma pipeta, o óleo foi coletado e acondicionado em frasco de vidro âmbar e armazenado em temperatura de refrigeração $\left(2-8^{\circ} \mathrm{C}\right)$.

Preparação das diluições do óleo essencial $O$ teste de atividade antimicrobiana foi

Rev. Bras. PI. Med., Campinas, v.16, n.2, p.225-230, 2014. 
realizado com o óleo essencial $P$. emarginatus puro $(100 \%)$ e em emulsões diluídas nas seguintes concentrações: $32 \%, 16 \%, 8 \%, 4 \%, 2 \%, 1 \%$ e 0,5\% (ALLEGRINI et al., 1973). Em um tubo de ensaio previamente esterilizado foi colocado 1,6 $\mathrm{mL}$ do óleo essencial, $0,04 \mathrm{~mL}$ de Tween 80 (Sigma ChemicalSt. Louis, MO, USA), acrescentado água destilada estéril em quantidade suficiente para $5 \mathrm{~mL}$. Em seguida, a emulsão formada foi homogeneizada manualmente durante 5 minutos obtendo-se emulsão na concentração de $32 \%$ sendo então diluídas em série à razão de 2 .

\section{Determinação da atividade antimicrobiana}

\section{microbianos}

\section{Preparo e Padronização dos Inóculos}

Para o preparo dos inóculos bacterianos foram utilizadas as cepas de Staphylococcus aureus ATCC 25923, Escherichia coli ATCC 25922 e Pseudomonas aeruginosa ATCC 27953. Cada cepa bacteriana foi transferida do meio de manutenção para o caldo $\mathrm{BHI}$ e incubadas à $37^{\circ} \mathrm{C}$ por $18-24$ horas. Após esse período foram semeadas em ágar Mueller-Hinton (MERCK SA, São Paulo, Brasil) e incubadas a $37^{\circ} \mathrm{C}$ por $18-24$ horas, para observação de possível contaminação.

Foram selecionadas 3 a 4 colônias do micro-organismo semeado em Ágar Mueller-Hinton as quais foram transferidas para tubo de ensaio contendo $2 \mathrm{~mL}$ de solução $\mathrm{NaCl} 0,85 \%$ estéril, a fim de obter uma turvação equivalente a escala de 0,5 de MacFarland (CLSI, 2005). Como controle negativo foi utilizado o Tween 80 (polissorbato), na maior concentração utilizada nesta pesquisa $(0,8 \%)$. Como controle positivo foram utilizados discos de

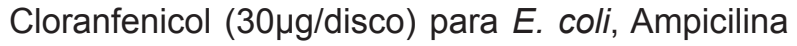

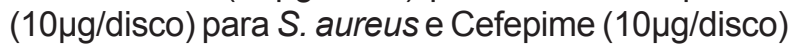
para $P$. aeruginosa, obtidos comercialmente (DME, Araçatuba, São Paulo, Brasil).

\section{Avaliação da Atividade Antimicrobiana}

Os testes para a verificação da atividade antimicrobiana do óleo essencial foram realizados no Laboratório de Pesquisa de Atividade Antimicrobiana da Universidade Estadual da Paraíba - Campina Grande - PB. Foi utilizado o método de difusão em meio sólido, processo cavidade-placa (CLSI, 2005).

O semeio foi realizado pela técnica de pour plate, inoculando-se $1 \mathrm{~mL}$ da suspensão bacteriana (com turbidez equivalente a escala 0,5 de MacFarland), em uma placa de Petri $(150 \times 15 \mathrm{~mm})$ sendo em seguida adicionado aproximadamente 50 $m L$ do Ágar Mueller-Hinton à $45^{\circ} \mathrm{C}$, quantidade esta suficiente para formar uma camada de ágar de 4 $\mathrm{mm}$ de espessura. Essa mistura (inóculo + meio de cultura) foi homogeneizada através de movimentos circulatórios (8 vezes). Após solidificação do meio foram realizadas cavidades com cânulas de plástico estéreis de $6 \mathrm{~mm}$ de diâmetro, nas quais foram adicionadas $5 \mu \mathrm{L}$ de Ágar Mueller-Hinton para vedar a cavidade e evitar que o óleo e as emulsões extravasem. Em seguida, acrescentou-se $50 \mu \mathrm{L}$ de cada concentração do óleo a ser testado. Após esta etapa, as placas foram incubadas à $37^{\circ} \mathrm{C} / 24$ horas. Todos os ensaios foram realizados em duplicata. Foram consideradas com atividade antimicrobiana as soluções que apresentaram halos de inibição de crescimento bacteriano com diâmetro $\geq 8 \mathrm{~mm}$ (CATÃO, 2007).

\section{Análise Estatística}

Os dados foram analisados utilizando $o$ programa GraphPad Prism versão 5.01.

\section{RESULTADOS E DISCUSSÃO}

A hidrodestilação, procedimento utilizado para extração do óleo essencial das sementes de $P$. emarginatus, apresentou rendimento de $1,25 \%(\mathrm{~m} / \mathrm{v})$, considerado baixo em relação ao valor obtido por Dutra et al. (2008), que conseguiu rendimento de $3,9 \%$ empregando o mesmo método de extração para o óleo essencial de $P$. emarginatus. Esta diferença quantitativa entre os rendimentos encontrados nos estudos citados anteriormente pode ser decorrente de diversos fatores, dentre eles: local de crescimento da planta, hora em que a planta foi coletada, luminosidade, altitude, temperatura ambiente e nível pluviométrico, que podem ter efeitos críticos tanto na quantidade quanto na qualidade dos óleos essenciais.

Os ensaios de atividade antibacteriana com o óleo essencial de sucupira e suas diluições não apresentaram atividade antimicrobiana contra as bactérias estudadas. As cepas foram sensíveis aos antimicrobianos testados no controle positivo, mostrando que o ensaio foi realizado de forma adequada (Tabela 1).

O dispersante Tween 80 não formou halo de inibição de crescimento em nenhuma das bactérias testadas. A ausência de poder antibacteriano do polissorbato já era aguardada uma vez que estudos descritos na literatura comprovam que o mesmo não produz efeitos contra as espécies de cepas testadas (VIEIRA et al., 2005; COSTA et al., 2008).

Ainda são poucos os trabalhos que relatam a atividade antimicrobiana do óleo essencial da $P$. emarginatus frente às espécies utilizadas neste estudo; entretanto, foram registrados dados de atividade antimicrobiana sobre as linhagens fitopatogênicas de fungos, Alternaria brassicae, Fusarium oxysporum, Rhizoctonia solani e Ceratocystis fimbriata, e das cepas bacterianas de 
TABELA 1. Atividade Antimicrobiana do óleo essencial puro de $P$. emarginatus e suas diluições frente à cepas de bactérias Gram - positivas e Gram negativas

\begin{tabular}{|c|c|c|c|c|c|c|c|c|c|c|c|}
\hline \multirow{2}{*}{ Cepas } & \multicolumn{8}{|c|}{ Concentração do Óleo Essencial / } & \multirow{2}{*}{$\begin{array}{c}\text { Controle } \\
\text { Negativo } \\
\text { Tween }\end{array}$} & \multirow{2}{*}{$\begin{array}{c}\text { Controle } \\
\text { Positivo (mm) } \\
\text { Antibióticos }\end{array}$} & \multirow{2}{*}{$\begin{array}{c}\text { Desvio Padrão } \\
(\mathbf{m m})\end{array}$} \\
\hline & $0,5 \%$ & $1 \%$ & $\frac{F}{2 \%}$ & $4 \%$ & $\frac{1(\geq 8}{8 \%}$ & $\frac{\mathrm{mm})}{16 \%}$ & $32 \%$ & $100 \%$ & & & \\
\hline $\begin{array}{l}\text { E. coli } \\
\text { ATCC } 25922\end{array}$ & - & - & - & - & - & - & - & - & - & $26^{*}$ & $1,414^{*}$ \\
\hline $\begin{array}{l}\text { S. aureus } \\
\text { ATCC } 25923\end{array}$ & - & - & - & - & - & - & - & - & - & $35^{* *}$ & $0,707^{* *}$ \\
\hline $\begin{array}{l}\text { P. aeruginosa } \\
\text { ATCC } 27853\end{array}$ & - & - & - & - & - & - & - & - & - & $27^{* * *}$ & $1,414^{* * *}$ \\
\hline
\end{tabular}

\footnotetext{
-: tamanho do halo de inibição de crescimento $\geq 8 \mathbf{~ m m}$;

* tamanho do halo de inibição de crescimento: Cloranfenicol (30 $\mu \mathrm{g} / \mathrm{disco})$;

** tamanho do halo de inibição de crescimento: Ampicilina (10 $\mu \mathrm{g} / \mathrm{disco})$;

*** tamanho do halo de inibição de crescimento: Cefepime (10 $\mu \mathrm{g} / \mathrm{disco})$;
}

Clavibacter michiganensis subsp. michiganensis, Pseudomonas syringae e Xanthomonas campestris pv. Campestres (SILVA et al., 2005) .

Silva et al. (2005) utilizaram o óleo essencial da fava da sucupira como agente antimicrobiano em micro-organismos fitopatogênicos, onde constataram que o óleo essencial da sucupira à $10 \%$ foi capaz de inibir o desenvolvimento micelial de Alternaria brassicae, Fusarium oxysporum, Rhizoctonia solani e Ceratocystis fimbriata, bem como de linhagens bacterianas de Clavibacter michiganensis subsp. michiganensis, Xanthomonas campestris pv. Campestris e Pseudomonas syringae.

Segundo Brandão et al. (2002), seus frutos são utilizados na forma de decocção em gargarejos no tratamento das dores de garganta. O uso do decocto das sementes da sucupira foi constatado na cidade de Itaueira - PI, onde se fez a coleta das informações etnofarmacológicas da sucupira. Suas sementes também são utilizadas na medicina popular há alguns anos na forma de macerados (DUTRA et al., 2008).

Esta divergência de atividade antimicrobiana encontrada entre o estudo de Silva et al. (2005) e os resultados deste estudo pode ser decorrente, dentre outros fatores, dos métodos de extração escolhidos, posto que Silva et al. (2005) utilizaram o solvente acetato de etila, técnica diferente da empregada neste estudo que utilizou hidrodestilação, e também das linhagens microbianas testadas que podem apresentar diferentes perfis de sensibilidade aos agentes antimicrobianos.

Outros trabalhos de avaliação da atividade antimicrobiana de sementes de $P$. emarginatus também utilizaram extratos (GONÇALVES et al., 2005). De acordo com estes autores, o extrato hidroalcoólico da semente da sucupira a $10 \%$ apresentou, atividade antimicrobiana frente a Proteus mirabilis, porém foi ineficaz frente as cepas de E. coli, S. aureus e P. aeruginosa. Estes dados assemelham-se aos encontrados neste estudo, apesar de utilizar técnica diferente de extração de compostos vegetais. Este fato permite sugerir que, independentemente do tipo do produto obtido (óleo ou extrato) das sementes da sucupira, os mesmos não apresentam atividade antimicrobiana frente à $S$. aureus, E. coli e $P$. aeruginosa.

Os óleos essenciais são constituídos por muitas substâncias com possíveis atividades biológicas, de modo que era esperado encontrar resultado positivo em relação à atividade antibacteriana do óleo essencial de $P$. emarginatus. Entretanto, este resultado não é único e nem restrito ao óleo essencial da semente de sucupira visto que outros autores obtiveram, anteriormente, resultados semelhantes estudando diferentes amostras de óleo de Carapa guianensis Aubl. (andiroba), Copaifera officinalis (copaíba) e Allium sativum L. (alho), frente à Staphylococcus aureus ATCC 6538, Escherichia coli ATCC 8739 e Pseudomonas aeruginosa ATCC 9027 (PACKER, LUZ, 2007).

A inatividade antibacteriana do óleo essencial de sucupira foi detectada pela incapacidade de produzir halos de inibição de crescimento frente ao Staphylococcus aureus ATCC 25923, linhagem utilizada como representante do grupo das bactérias Gram positivas.

O comportamento do óleo de sucupira também foi semelhante quando testado frente as linhagens de $P$. aeruginosa ATCC 27853 e de $E$. coli ATCC 25922 .

Souza et al. (2004), verificaram que em dezoito extratos de plantas analisadas nenhum deles apresentou atividade antimicrobiana frente a $E$. coli. Uma hipótese sobre esta ineficiência antibacteriana dos óleos vegetais sobre bactérias Gram negativas pode ser atribuída pela ação da membrana externa, onde a presença dos fosfolipídios em sua estrutura 
a torna quase impermeável aos componentes lipofílicos e, juntamente com a atividade de bomba de efluxo, constituem mecanismos especializados em expulsar substâncias exógenas estranhas protegendo os micro-organismos de concentrações inibitórias ou letais dos agentes antimicrobianos, o que resulta em elevada resistência intrínseca a uma série de antimicrobianos (NIKAIDO; VAARA, 1985; HANCOCK; BELL, 1988; NIKAIDO, 1989; KÖHLER, 1999).

Esses dados demonstram que a suscetibilidade dos micro-organismos frente aos óleos essenciais nem sempre é observada de forma positiva, respondendo de maneira particular a cada composto, metodologia empregada e espécie microbiana estudada, recebendo influencias dos vários fatores aos quais estão vinculados.

\section{CONCLUSÃO}

O óleo essencial extraído das sementes de Pterodon emarginatus não apresentou atividade antibacteriana frentes as cepas de Staphylococcus aureus ATCC 25923, Pseudomonas aeruginosa ATCC 27853 e Escherichia coli ATCC 25922. A ineficácia do óleo essencial extraído frente a estes micro-organismos sugere que a amostra de sementes de Pterodon emarginatus Vogel testada não apresentou substâncias químicas potencialmente ativas sobre as linhagens analisadas.

\section{REFERÊNCIA}

ALLEGRINI, M.; SIMÉON, M.; MAILLOS, H.; BOILOOT, A. Ėmulsions et applications en microbiologie. Travaux de La Société de Phamacie de Montpellier, v. 33, p.73-86, 1973.

BAQUERO F. AND BLÁZQUEZ J. (1997). Evolution of antibiotic resistance, Tree 12:482-487.

BRANDÃO, M.; LACA - BUENDIA, J.P.; MACEDO, J.F. Árvores nativas e exóticas do Estado de Minas Gerais. Informe Agropecuário, v. 23, n. 217, p. 264-265, 2002.

CARVALHO, J.C.T.; SERTIE, J.A.A.; BARBOSA, M.V.J.; PATRICIO, K.C.M.; CAPUTO, L.R.G.; SARTI S, J.; FERREIRA, L.P.; BASTOS, J.K. Anti-inflammatory activity of the crude extract from the fruits of Pterodon emarginatus Vog. Journal of Ethnopharmacology, v. 64, p. 127-133, 1999.

CATÃO, R. M. R. Atividade antimicrobiana e efeitos biológicos de riparinas sobre bactérias e fungos leveduriformes. 2007. 126 p. Tese de Doutorado Universidade Federal da Paraíba, João Pessoa.

CLINICAL LABORATORY STANDARDS INSTITUT CLSI. - Padronização dos Testes de Sensibilidade a Antimicrobianos por Disco-difusão: Norma Aprovada - 8a ed. M2-A8. 23 (1). Substitui a Norma M2-A7, 20 (1), 2005.

COSTA, J.G.M.; RODRIGUES, F.F.G.; ANGÉLICO, E.C.;
PEREIRA, C.K.B.; SOUZA, E.O.; CALDAS, G.F.R.; SILVA, M.R.; SANTOS, N.K.A.; MOTA, M.L.; SANTOS, P.F. Composição química e avaliação da atividade antibacteriana e toxicidade do óleo essencial de Croton zehntneri (variedade estragol). Revista Brasileira de Farmacognosia, v. 18, n. 4, p. 583-586, 2008.

DUARTE, M. C. T. Atividade antimicrobiana de plantas medicinais e aromáticas utilizadas no Brasil. Multiciência, Campinas, n. 7, 2006.

DUTRA, R.C.; TREVIZANI, R.; PITTELLA, F.; BARBOSA, N.R. Antinociceptive Activity of the Essential Oil and Fractions of Pterodon emarginatus Vogel Seeds. Latin American Journal of Pharmacy, v. 27, n. 6, p. 865 870, 2008.

GALCERAN, C.B.; SERTIE, J.A.A.; LIMA, C.S.; CARVALHO, J.C.T. Anti-inflammatory and analgesic effects of $6 a, 7 b$-dihydroxy-vouacapan-17b-oic acid isolated from Pterodon emarginatus Vog. Fruits. Inflammopharmacol, n.19, p.139-143, 2011.

GONÇALVES, A.L.; FILHO, A.A.F.; MENEZES, H. Estudo comparativo da atividade antimicrobiana de extratos de algumas árvores nativas. Arquivos do Instituto de Biologia, v. 72, n. 3, p. 353-358, 2005.

HANCOCK, R.E.W.; BELL, A. Antibiotic uptake into Gram-negative bacteria. European Journal Clinical Microbiological and Infectious Diseases, v. 7, n. 6, p. 713-720, 1988.

KÖHLER, T.; PECHÈRE, J.C.; PLÉSIAT, P. Bacterial antibiotic efflux systems of medical importance. Cellular and Molecular Life Sciences, v. 56, p. 771-778, 1999.

LÓPEZ, C.A.A. Considerações gerais sobre plantas medicinais. Ambiente: Gestão e Desenvolvimento v. 1, n. 1, p. 19-27, 2006.

MORAES, W.F. DE; MATOS, L.G.DE; NASCIMENTO, M.V.M.; PAULA, J.R.DE; BARA, M.T.F.; CUNHA, L.C.DA; VALADARES, M.C.; COSTA, E.A. Anti-inflammatory and anti-nociceptive effects of Pterodon emarginatus stem bark alcohol extract. Pharmaceutical Biology., n.47, v.2, p.146-150, 2009.

NASCIMENTO, G.G.F. et al. Antibacterial activity of plant extracts and phytochemicals on antibiotic-resistant bacteria. Brazilian Journal of Microbiology, São Paulo, v.31, n.2, p.247-256, 2000.

NEVES, F.A.; SANTOS, D.R.; LUCENA, P.A.; SOUZA JÚNIOR, G.F.DE; OLIVEIRA, C.M.A.DE; SILVA, M.R.R. Teste de suscetibilidade de dermatófitos ao extrato semissintético Hexanóico de pterodon emarginatus Vogel. Revista Eletrônica de Farmácia, v.4, n.2, p.4446, 2007.

NIKAIDO, H.; VAARA, M. Molecular basis of bacterial outer membrane permeability. Microbiological Reviews, v. 49, n. 1, p. 1-32, 1985

NIKAIDO, H. Outer membrane barrier as a mechanism of antimicrobial resistance. Antimicrobial Agents and Chemotherapy. v. 33, p. 1831-1836, 1989.

PACKER, J.F.; LUZ M.M.S. Método para avaliação e pesquisa da atividade antimicrobiana de produtos de origem natural. Revista Brasileira de Farmacognosia, v. 17, n. 1, p. 102-107, 2007.

PALMEIRA,J.D.; FERREIRA, S.B.; SOUZA, J.H.; ALMEIDA, J.M.; FIGUEIREDO, M.C.P.; PEQUENO, A.S.; ARRUDA, T.A.; ANTUNES, R.M.P.; CATAO, R.M.R. Avaliacao da atividade antimicrobiana in vitro 
e determinação da concentracao inibitoria minima (CIM) de extratos hidroalcoolico de angico sobre cepas de Staphylococcus aureus. Revista Brasileira de Análises Clínicas, v.42, n.1, p.33-37, 2010.

PAULA, F.B.A.; GOUVÊA, C.M.C.P.; ALFREDO, P.P.; SALGADO, I. Protective action of a hexane crude extract of Pterodon emarginatus fruits against oxidative and nitrosative stress induced by acute exercise in rats. BMC Complementary and Alternative Medicine, n.17, v.5, 2005.

RIZZINI, C.T. Manual de dendrologia brasileira: árvores e madeiras úteis Brasil. 2. ed. São Paulo: Edgard Blucher, 1978. 255p.

SANTOS, A.P.; ZATTA, D.T.; MORAES, W.F.; BARA, M.T.F.; FERRI, P.H.; SILVA, M.R.R.; PAULA, J.R. Composição química, atividade antimicrobiana do óleo essencial e ocorrência de esteróides nas folhas de Pterodon emarginatus Vogel, Fabaceae. Revista Brasielira de Farmacognosia, n.20, v.6, p.891-896, 2010.
SILVA, I.D.; TAKATSUKA, F.S.; ROCHA, M.R.; CUNHA, M.G. Efeito do extrato de sucupira (Pterodon emarginatus Vog.) sobre o desenvolvimento de fungos e bactérias fitopatogênicos. Pesquisa Agropecuária Tropical, v. 35, n. 2, p. 109-115, 2005.

SIMÕES, C.M.O.; SCHENKEL, E.P.; GOSMANN,.G.; MELLO, J.C.P.; MENTZ, L.A.A.; PETROVICK, P.R.; Farmacognosia: da planta ao medicamento. 5 ed. Florianópolis: UFSC/UFRGS, 2003.

SOUZA, G.C.; HAAS,A.P.; VONPOSER, G.L.; SCHAPOVAL, E.E.; ELISABETSKY, E. Ethnopharmacological studies of antimicrobial remedies in the south of Brazil. Journal of Ethnopharmacology, v. 90, n. 1, p. 135-143, 2004.

VEIGA JUNIOR, V.F.; PINTO, A.C. Plantas medicinais: cura segura? Química Nova, n.3, v.28, p. 519-528, 2005.

VIEIRA, O.M.C.; SANTOS, M.H.; SILVA, G.A.; SIQUEIRA, A.M. Atividade antimicrobiana de Struthanthus vulgaris (erva-de-passarinho). Revista Brasileira de Farmacognosia, v. 15, n. 2, p. 149-154, 2005. 